\title{
Maternidade e colapso: consultas terapêuticas na gestação e pós-parto ${ }^{1}$
}

\author{
Tania Mara Marques Granato ${ }^{2}$ \\ Tania Maria José Aiello-Vaisberg \\ Pontifícia Universidade Católica de Campinas, Campinas-SP, Brasil
}

\begin{abstract}
Resumo: A partir de consultas terapêuticas com gestantes e mães, elaboramos cinco vinhetas clínicas a fim de investigar psicanaliticamente a hipótese de que estados psíquicos primitivos sejam engendrados pela maternidade. A perspectiva winnicottiana, segundo a qual, o terapeuta adota o holding como base de toda intervenção terapêutica, mostrou-se particularmente produtiva em termos do alívio ao sofrimento materno, assim como de uma apropriação genuína da maternidade. Algumas recomendações são feitas ao psicólogo clínico no sentido de redirecionar seu olhar para as necessidades maternas, dessa forma, facilitando o estabelecimento de uma relação mãe-bebê saudável a partir da promoção do bem-estar materno.
\end{abstract}

Palavras-chave: maternidade, gravidez, provisão ambiental (Winnicott), psicanálise.

\section{Maternity and breakdown: therapeutic consultations during pregnancy and postpartum}

\begin{abstract}
Five clinical vignettes were developed based on therapeutic consultations with pregnant women and mothers in order to psychoanalytically investigate the hypothesis that primitive psychic states are originated by motherhood. The winnicottian perspective, according to which therapists adopt the holding as the basis of every therapeutic intervention, was particularly productive in terms of relieving maternal suffering as well as to enable a personal appropriation of motherhood. Some recommendations are forwarded to psychologists with a view to redirect their focus to maternal needs so as to favor the establishment of a healthy mother-infant relationship, through the promotion of maternal well-being.
\end{abstract}

Keywords: motherhood, pregnancy, ambient provision (Winnicott), psychoanalysis.

\section{Maternidad y colapso: consultas terapéuticas en el embarazo y postparto}

Resumen: A partir de las consultas terapéuticas con embarazadas y madres elaboramos cinco viñetas clínicas a fin de investigar la hipótesis de que estados psíquicos primitivos sean engendrados por la maternidad. La perspectiva winnicottiana, en la cual el terapeuta adopta el holding como base de toda intervención terapéutica se ha mostrado productiva en términos del alivio del sufrimiento materno y de una apropiación genuina de la maternidad. Algunas recomendaciones son presentadas al psicólogo clínico, en el sentido de redireccionar su atención para las necesidades maternas, facilitando el establecimiento de una relación madre-hijo saludable, através de la promoción del bienestar materno.

Palabras clave: maternidad, embarazo, provisión ambiental (Winnicott), psicoanálisis.

Após dez anos de consultas terapêuticas (Winnicott, 1971) realizadas com mulheres que buscavam alívio para o sofrimento psíquico durante a gestação e/ou pós-parto, instigou-nos a hipótese de que a própria maternidade, como processo biopsicossocial, pudesse desencadear o desequilíbrio afetivo-emocional de que nossas pacientes se queixavam. Enquanto algumas mulheres relatavam agravamento de sintomatologia anterior, por ocasião da gravidez, outras se queixavam de mudanças psicológicas importantes, as quais interferiam nos relacionamentos pessoais e em seu próprio bem-estar. A fim de compreender os elementos que se mostraram terapêuticos em nossa prática, revisitaremos cinco casos clínicos e alguns dos autores que inspiraram nossa clínica winnicottiana da maternidade.

A experiência da maternidade (Winnicott, 1956/1988a) é usualmente acompanhada por um aumento da sensibilidade

1 Este texto foi revisado seguindo Acordo Ortográfico da Língua Portuguesa (1990), em vigor a partir de $1^{\circ}$ de janeiro de 2009.

2 Endereço para correspondência:

Dra. Tania Mara Marques Granato. Rua Bernardino de Campos, 318/114 CEP 04.602-001. São Paulo-SP, Brasil. E-mail: taniagranato@uol.com.br materna, além do retraimento psicológico da mãe que, renunciando a seus interesses habituais, passa a compor com o bebê uma unidade autônoma e relativamente isolada, o que garante os cuidados básicos ao recém-nascido. No contexto de uma parceria tão afinada, como poderíamos compreender o sofrimento materno que é engendrado pela própria maternidade?

Winnicott (1954/1988b) cuidou de distinguir o retraimento materno do processo de regressão, fenômeno psicopatológico prejudicial ao estabelecimento de uma relação mãe-bebê saudável, ainda que justificado como estratégia clínica em contexto psicanalítico específico (Winnicott, 1954/1988c). Seguindo a elaboração deste autor, poderíamos atribuir o sofrimento de algumas das pacientes que atendemos a um processo regressivo indesejável que comprometeria a tarefa materna, cujo requisito básico é a saúde mental da mãe. Uma mãe regredida terá dificuldades para cuidar de seu bebê, uma vez que, por força do movimento regressivo, ficará à mercê de necessidades mais primitivas.

Bleger (1967a) é outro autor que traz importantes contribuições ao nosso tema quando postula a existência de uma organização psíquica anterior à posição esquizoparanóide de Melanie Klein (1946/1985), a posição glischro-cárica, na 
qual predominariam a fusão e a não-diferenciação eu/não-eu. Um núcleo aglutinado, remanescente dessa primitiva organização, manter-se-ia na vida adulta como a "parte psicótica da personalidade", cuja elaboração promoveria a discriminação que abre caminho para os afetos e a simbolização. Uma vez conquistada a posição esquizoparanóide de discriminação, os esforços da dupla psicanalítica dirigir-se-iam para o campo da ambivalência e da integração, constituindo-se assim a posição depressiva.

Seguindo a conceituação de Bleger, ao observar regressão no lugar do habitual retraimento da dedicação materna saudável (Winnicott, 1949/1996), conduziríamos o trabalho terapêutico em termos da parte psicótica da paciente. Para acolher tais necessidades, sem perder de vista o amadurecimento emocional pretendido em qualquer tratamento psicológico e intensamente exigido pela função materna, é fundamental a clareza quanto ao enquadre oferecido, como bem observa Bleger (1967b).

Em contrapartida, vale lembrar que a provisão de um ambiente confiável ao paciente não implica em fundir-se com ele, numa aliança entre as partes psicóticas de um e de outro, como Bleger (1967b) adverte. Na realidade, serão as cuidadosas rupturas desse enquadre, tão delicadamente arranjado pelo terapeuta e prontamente utilizado pelo paciente, que proporcionarão crescimento emocional. Refletindo sobre a leitura que Bleger faz da situação terapêutica em tempos de simbiose e a conceituação de Winnicott (1956/1988a) sobre a preocupação materna primária, vemos que o terapeuta, como a mãe sensível, dosa a parcela de mundo externo segundo a tolerância do paciente, garantindo com tal medida a continuidade de seu existir. A mãe preocupada de Winnicott oferece o único tipo de relação que o bebê pode tolerar, dada a imaturidade emocional deste - as vivências simbióticas referidas por Bleger (1967a), enquanto o terapeuta confiável será, sobretudo, aquele que adapta suas intervenções ao ritmo de seu paciente.

Steiner (1993/1997a) dedicou-se ao estudo de organizações patológicas da personalidade, nas quais um refúgio psíquico é criado sempre que o contato com a realidade se torne insuportável. Tais refúgios não seriam privilégios de pacientes psicóticos, visto que se situariam na fronteira entre as posições kleinianas esquizoparanóide e depressiva, atuando como proteção contra esses dois tipos de ansiedade, porém tenderiam a exercer um maior controle sobre a personalidade naqueles quadros mais graves. De acordo com Steiner, tratar-se-ia de um desequilíbrio do mecanismo de identificação projetiva que, ao se tornar irreversível, enfraqueceria o ego, tornando-o cada vez mais dependente do refúgio, vivenciado como lugar ou objeto de proteção, mas também de aprisionamento e dominação.

Steiner (1993/1997b) aponta para o paradoxo que tais pacientes nos apresentam, uma vez que buscam ser compreendidos no sentido do holding, mas não suportam saber de seu estado psíquico, na linha da aquisição de insight. Oferecer a continência necessária, cuidando para que não nos aliemos à organização patológica do paciente, nem recorramos aos nossos próprios refúgios, é a solução entrevista por Steiner, que propõe a "receptividade flutuante" do analista como alternativa à "atenção flutuante". Tais formulações nos remetem a Winnicott (1971/1975a) e à forma dissociada que o fantasiar pode tomar. Uma de suas pacientes ensinou-lhe como o devaneio, em que se enredava por horas a fio, roubava-lhe a própria vida, restringindo suas ações no mundo, numa espécie de sequestro psíquico.

A contraparte de Winnicott (1960/1990a) diz respeito ao mecanismo de proteção do verdadeiro self, que, diante da impossibilidade de se expressar, constituiria um falso self para dar conta das demandas da realidade, fazendo-se porta-voz e protetor do verdadeiro self. A despeito do sucesso alcançado por tais pessoas, a futilidade e o vazio caracterizam a vida assim forjada como fachada. Tanto a paciente de Winnicott que devaneava quanto os pacientes "refugiados" de Steiner mantinham vidas aparentemente saudáveis, ocultando a impossibilidade de um viver autêntico.

Searles (1967/1999a), em seus esforços para tratar psicanaliticamente os pacientes de uma clínica psiquiátrica, parece ter radicalizado a concepção, depois compartilhada por toda uma geração de psicanalistas, influenciados pela antipsiquiatria, que insistia na contribuição quase unilateral do ambiente na geração da doença mental. Retirando a responsabilidade do paciente esquizofrênico sobre sua doença, fizeram com que esta recaísse sobre seus pais. Concebendo-os como guias ou intérpretes dos filhos, Searles afirmava que percepções realistas, em oposição às delirantes, só poderiam emergir em um clima emocional de confiança mútua, a partir do qual se processaria a diferenciação que falta ao paciente esquizofrênico. Paradoxalmente, o mesmo Searles lembra que percepções acuradas não só promovem como requerem individuação, deixando-nos na posição insustentável de uma Psicologia moralista que busca culpados pela doença mental.

Ao narrar o percurso do tratamento psicanalítico de uma paciente esquizofrênica e suas parcas aquisições ao longo de 18 anos de psicanálise, Searles (1972/1999b) ilustra a quase permanente inabilidade de sua paciente para a diferenciação entre linguagem metafórica e concreta, elementos animados e inanimados da realidade, formas humanas e inumanas de vida, homens e mulheres, crianças e adultos, fantasia e realidade ou mesmo entre ideias e pessoas. No entanto, Searles atribui os tênues sucessos alcançados à legitimação das percepções da paciente quando foi capaz de associá-las ao que ele vivia em termos contratransferenciais.

Enquanto a Psiquiatria da época semeava o campo das causas endógenas, dispensando o exame das condições dramáticas do viver, Winnicott chamava a atenção dos psicanalistas para o papel do ambiente nos estágios precoces do desenvolvimento. A partir de sua experiência como pediatra, e mais tarde como psicanalista, pôde observar cuidadosamente a relação mãe-bebê, identificando nela características que se assemelhavam ao setting freudiano em seus elementos de estabilidade e confiabilidade. 
A despeito do alento que tal visão trouxe àqueles que, como Winnicott (1954/1988c), acreditavam nos benefícios de um ambiente terapêutico, ainda que oferecido a posteriori àqueles que foram privados de um cuidado materno adequado, tal concepção nos conduziu também à equivocada sobrevalorização do fator ambiental. Substituindo a organicidade pela maternidade como suporte para o ego do bebê, Winnicott (1956/1988a, 1960/1990b, 1962/1990c, 1963/1994a) salvou o indivíduo da prisão de sua biologia para lançá-lo no colo da mãe responsável pela saúde mental da prole. Apesar da concordância irrestrita com algumas das ideias winnicottianas, como a que sublinha a importância do setting terapêutico, no qual está incluída a pessoa do terapeuta, na criação das condições facilitadoras para o desenvolvimento emocional do paciente, recusamos concepções reducionistas como as adotadas pela Psiquiatria e Psicanálise ortodoxas. O próprio Winnicott (1971/1975b) vai admitir, mais tarde, o fator hereditário na esquizofrenia, mantendo-se, no entanto, alerta contra qualquer teorização que divorcie o indivíduo de seu drama. É com esse Winnicott mais moderno que pretendemos dialogar.

Ferenczi (1933/2002) já defendia uma relação terapêutica mais autêntica como única forma de oferecer um ambiente confiável ao paciente e, dessa forma, a possibilidade de viver uma experiência nova. Refletindo sobre o abuso sexual infantil e a "confusão de línguas" instaurada pelas diferenças entre o amor infantil e o adulto, Ferenczi nos aconselha que agucemos nossa escuta, tendo em mente que estamos sempre lidando com o lado infantil de nossos pacientes, situação na qual o cuidado materno será sempre mais apropriado que explicações intelectualizadas.

Ao lado de autores contemporâneos como Couto, Tachibana e Aiello-Vaisberg (2007), Ogden (2005), Safra (2004) e Spurling (2008), apenas para citar alguns, subscrevemo-nos à noção de que o setting terapêutico desempenha as mesmas funções do ambiente que é suficientemente bom na infância, garantindo o bem-estar físico e psicológico através do respeito ao ritmo de desenvolvimento emocional do indivíduo (AielloVaisberg \& Granato, 2006; Aiello-Vaisberg, Silva, Granato, \& Felice, 2003; Granato, 2002, 2005, 2007; Granato \& AielloVaisberg, 2003a, 2003b, 2004, 2005, 2008). Ressaltamos ainda que, para além das expectativas que uma sociedade nutra em relação à figura materna, a mãe estará igualmente sujeita aos revezes da psicologia, da cultura e da biologia.

Com o objetivo de investigar a hipótese de que estados psíquicos primitivos sejam engendrados pela maternidade, articularemos cinco vinhetas clínicas às ideias psicanalíticas que fundamentam este trabalho.

\section{Método}

\section{Participantes}

Selecionamos cinco mulheres (de 21 a 38 anos) dentre nossas pacientes, como ilustração do que observávamos em maior ou menor grau na maioria delas. Três eram primíparas e duas estavam em sua terceira gestação. Todas eram casadas, uma desempregada, outra desempenhava tarefas domésticas e as demais trabalhavam fora do lar. Apenas uma delas tinha nível superior, enquanto as demais apresentavam nível médio de estudo.

\section{Contexto/local do estudo}

As consultas terapêuticas tiveram lugar em uma universidade pública, no contexto de um serviço de atendimento psicológico gratuito oferecido a gestantes e mães no pósparto, a partir do referencial winnicottiano de sustentação emocional, visando ao alívio do sofrimento psíquico e ao consequente fortalecimento do vínculo mãe-bebê. Além dos objetivos psicoterapêuticos, pudemos investigar, por meio do material clínico acumulado, o processo pelo qual a mulher se torna mãe, desenvolvendo pesquisas na área da maternidade, assim como novas estratégias clínicas.

\section{Procedimento}

Foram realizadas consultas terapêuticas semanais e individuais durante a gestação (entre o $3^{\circ}$ e o $9^{\circ}$ mês) e o pós-parto ( $1^{\circ}$ ao $6^{\circ}$ mês), em função da demanda de cada paciente, isto é, havia mulheres que solicitavam duas ou três consultas e outras que sentiam necessidade de acompanhamento psicológico do início da gravidez até o pós-parto. Quanto aos cuidados éticos, cabe salientar que este trabalho foi guiado pelas orientações éticas da universidade onde se desenvolveu, desde seu início, como trabalho clínico. Cumpre ressaltar que tais cuidados sempre tiveram por norte o sigilo profissional e os objetivos psicoterapêuticos em prol da preservação do vínculo terapêutico. As vinhetas clínicas são incluídas como ilustração do processo que observamos em nossa prática, além de terem sido alteradas para evitar o reconhecimento das identidades das pacientes.

\section{Análise de dados}

Diante dos cinco casos clínicos selecionados, elaboramos vinhetas a partir das quais pudéssemos observar a presença ou ameaça de colapso materno e sua relação com a maternidade. Interpretando tais dados à luz de ideias psicanalíticas, fizemos uso do método psicanalítico na investigação de nossa hipótese principal, considerando nossos dados como material associativo.

\section{Resultados}

A seguir apresentamos, sob a forma de vinhetas, cinco casos clínicos selecionados para a ilustração de processos psicológicos que podem acompanhar a experiência materna, comprometendo o bem-estar da dupla mãe-bebê.

\section{Amor de filha}

Paula percebeu-se mais sensível e "chorosa" a partir do segundo trimestre de gestação. Filha de pai militar severo e mãe submissa, encontrou refúgio do ambiente hostil 
da infância numa relação conjugal idealizada. Já nos primeiros meses que se seguiram ao parto, Paula desenvolveu um intenso vínculo com a filha recém-nascida, afastando-se, paulatinamente, de seus pais, dos sogros e do marido. Paralelamente à intimidade crescente que vivia na relação com a filha, conflitos infantis eram trazidos à tona, como o desprezo que sentia pela mãe e a admiração que secretamente nutria pelo pai. O isolamento de Paula, sua preocupação com a autonomia da filha e o horror de ser abandonada foram os elementos centrais do trabalho terapêutico, que se prolongou até os 18 meses de seu bebê, através de consultas, telefonemas e e-mails. A despeito dos obstáculos criados por uma vivência paranóide da maternidade, a menininha, que acompanhou a mãe em todas as sessões, desenvolvia-se de maneira saudável, mostrando-se sempre alegre e sociável, sugerindo-nos que a mãe, amparada pelo holding terapêutico, estava provendo-lhe os cuidados básicos.

\section{Quero meu filho de volta}

Grávida do terceiro filho, Iolanda buscou ajuda psicológica para a própria hostilidade perante a gravidez indesejada. Acolhida em seu ódio, decidiu-se por deixar vir ao mundo aquele bebê, com quem desenvolveu uma relação saudável e gratificante. Mulher prática e determinada, Iolanda experimentou, pela primeira vez, a precariedade do viver ao perder seu bebê de oito meses para uma pneumonia devastadora. Retomou a psicoterapia, reerguendo-se depois de um ano, quando descobrimos que seu vigor se mantinha, em tempos tão difíceis, pela esperança de engravidar novamente. Acalentado em silêncio, o sonho foi bruscamente interrompido pelo veredicto de seu marido, que não tinha a menor intenção de ter outro filho. Devastada pelo luto retomado, seguiramse dois anos de tratamento psiquiátrico. Em uma das últimas conversas que tivemos, Iolanda afirmou ter se decidido pelo mundo dos vivos, embora, à noite, continuasse a sonhar com bebês...

\section{Eu sei que eи vou morrer}

Mãe de dois jovens e grávida aos 38 anos, Maria se desesperou, sobretudo porque acabara de perder o emprego. Gritando que morreria no parto, foi levada ao pronto-socorro, onde foi medicada com antidepressivos e encaminhada para nosso serviço. Testemunha do suicídio do pai, Maria era vítima frequente da brincadeira dos irmãos que afirmavam ter sido ela adotada, ideia reforçada pelo fato de ter sido enviada, aos sete anos, para trabalhar como empregada doméstica. Durante toda a gravidez, convivemos com o medo que Maria sentia de morrer no parto. Imaginou mil modos de se matar durante a gravidez, o que anteciparia o anunciado desfecho. Fortaleceu-se com o amparo que recebia de profissionais, amigos e parentes, dando à luz a uma menina saudável.

Durante os seis meses que se seguiram ao parto, Maria e sua filha comemoraram as primeiras mamadas de uma e o primeiro amamentar da outra, o que deu à mãe uma inusitada sensação de completude. Inúmeros problemas sobrevieram, como a crônica dificuldade financeira, episódios de alcoolismo do marido, o ciúme da filha mais velha e o câncer do sogro, mas foram superados. Quando seu atendimento chegou ao fim, ela não cansava de repetir que não teria conseguido passar pelo que passou sem a ajuda da psicoterapeuta.

\section{Então a vida é assim?}

Foi assim que Alice encerrou suas consultas depois de um ano de atendimento, metade dele realizado durante a gravidez de sua primeira filha. Alice tinha sofrido uma primeira crise de pânico aos 16 anos de idade, logo após o falecimento de seu pai, com quem teve uma relação bastante conflituosa. Ora sóbrio, ora alcoolizado, oferecia-se como figura ambígua para Alice, que insuficientemente apoiada por uma mãe assustadiça e imprevisível, chegou a desejar a morte do pai - destino que se cumpriu. Depois de "anos de análise", Alice buscava um "tratamento diferente" frente à nova crise de ansiedade, desencadeada pela gravidez. Manifestou um grande interesse pela Oficina de Costura (uma das modalidades de nossa clínica), onde confeccionou uma colcha de retalhos e, mais tarde, uma boneca-flor (Dolto, 1949/1993). Ali costuramos e conversamos sobre sua vida, seus medos e suas expectativas, alinhavamos sonhos e arrematamos problemas que Alice julgava serem sinais de infelicidade.

Era comum que pesadelos acordassem Alice, que suada e ofegante em seu medo de morrer, acalmava-se somente depois de uma extenuante caminhada noturna. Frente aos primeiros movimentos do bebê em seu ventre e quando este começou a aumentar, também entrou em pânico, imaginando que suas vísceras seriam comprimidas a ponto de faltar-lhe $o$ ar. Entretanto, à medida que a gravidez e a psicoterapia progrediam, a respiração ofegante dava lugar ao ritmo relaxado e Alice prosseguia em seu amadurecimento.

\section{Eu sou uma farsa}

Rosa experimentou uma espécie de renascimento ao tornar-se mãe, processo que acompanhamos desde o início da gravidez até os dois anos de seu filho. Grávida e bulímica, foi encaminhada, em caráter de urgência, por sua obstetra. Não sabíamos que, por trás daquela moça de aparência frágil, dependente e limitada em suas realizações profissionais, ocultavam-se o talento e a sensibilidade artística, cujos produtos ficaram trancados no sótão de sua casa, por muitos anos. Rosa escondia naquelas gavetas empoeiradas todos os seus trabalhos, protegendo-se da exposição, da crítica e, principalmente, do olhar materno. Mostrar-se feia, burra e retraída parecia-lhe ser a maneira mais segura de preservar o belo. Em contrapartida, a pobreza externa - camuflagem de um mundo interior rico - distanciava Rosa de si mesma, resultando na vida medíocre que levava.

Considerada até então a "débil mental da família", Rosa surpreendeu a todos quando deu à luz a um menino saudável e, sobretudo, ao mostrar-se mãe dedicada. Sustentada pela relação terapêutica, ousou levantar o grosso véu que cobria sua existência e mostrar quem realmente era à mãe, aos parentes 
e aos colegas de trabalho, vivendo a maternidade como crise que alavanca o crescimento emocional.

\section{Discussão}

Embora as mães aqui apresentadas tenham sido capazes de se render ao estado preocupado de Winnicott (1956/1988a), colocando-se física e psiquicamente à disposição de seus bebês, atendendo-os em suas necessidades básicas, cada uma delas viveu a maternidade como experiência emocional impactante. Como vimos, a emergência de ansiedades primitivas engendradas pelo processo de maternidade contribui para o colapso das defesas que mantinham a estabilidade emocional anterior, no entanto, tal desestruturação pode se constituir como momento de retomada do desenvolvimento emocional ao ser cuidada em ambiente terapêutico.

O retraimento de Paula superou os limites do que é usual numa relação materna saudável, resultando no isolamento social da dupla, provavelmente como consequência da reativação de núcleos psicóticos da personalidade, seguindo a conceituação de Bleger (1967a). Caso os apelos simbióticos (Bleger, 1967b) de Paula predominassem sobre as necessidades do bebê, todo um processo de maternagem estaria ameaçado pelo colapso materno. Todavia, o processo regressivo permaneceu circunscrito à relação terapêutica, onde a terapeuta atuava na linha do cuidado materno, ou seja, do holding terapêutico, salvaguardando a relação mãe-bebê.

Iolanda viveu a perda de seu bebê como sequestro do eu que lhe parecia atrelado à função materna, aprisionando-se num luto eterno que, apesar de compreendido e legitimado no encontro terapêutico (Searles, 1972/1999b), não a impediu de refugiar-se (Steiner, 1993/1997a) na promessa de que um outro bebê a resgataria da morte em vida. Mais próxima do delírio do que do sonhar, que é próprio do viver (Winnicott, 1971/1975a), Iolanda entrou em colapso, não em virtude de ter se tornado mãe, mas por deixar de ser. Fazendo um contraponto com nossos autores ambientalistas, observamos o mito do indivíduo imunizado pelo cuidado materno na infância ser demolido a cada atendimento clínico, em que acompanhamos "fortalezas" sendo derrubadas.

Maria e Alice também chamaram nossa atenção para o potencial desagregador da maternidade, experimentado por mulheres que sofreram com "depressão, pânico ou crises de loucura" durante a gravidez e, mais comumente, no pós-parto. Contudo, deram testemunho do potencial de recuperação dessas mulheres. Tais fatos clínicos nos autorizam a questionar outro mito psicanalítico: a ideia de que os problemas emocionais da mãe selam o destino do filho, a despeito das tendências inatas do bebê em direção ao próprio desenvolvimento emocional e do suporte social que a dupla mãe-bebê venha a receber.

Tendo superado o horror do parto, largamente compensado pelas alegrias da amamentação saudável, Maria solicitou ajuda terapêutica para retornar ao trabalho frente ao vazio instaurado pelo desmame. Foi, também, num ambiente de holding que Alice superou o pânico desencadeado durante a gestação, fortalecendo-se para a tarefa materna. Os antigos rituais de passagem (Van Gennep, 1908/1984) já sinalizavam a importância da sustentação social nas fases críticas do percurso de cada indivíduo rumo à maturidade. Como Alice, a mulher que titubeia no portal da maternidade necessita de gestos e palavras que a acalmem, guiem e ofereçam alternativas. Talvez Alice e sua terapeuta tenham simplesmente falado a mesma língua, como Ferenczi (1933/2002) aconselhava, e os efeitos mutativos tenham vindo como consequência natural de um ambiente no qual falar implica em ser ouvido.

Rosa havia tomado as impressões pessoais de sua mãe como provas de realidade e, desconsiderando as próprias percepções, decretou seu mundo como louco em oposição ao mundo "sadio" da mãe. Incapaz de discriminar-se da mãe, temendo perdê-la, precisou criar um mundo à parte (Steiner, 1993/1997a), onde pudesse relaxar e obter alguma gratificação. Horas de cinema, comilança e retraimento afastavamna das temidas invasões ambientais (Winnicott, 1965/1994b), mas também de si mesma.

A gravidez, o parto e o desamparo do bebê parecem evocar, no adulto e, mais particularmente na mãe, um campo de experiências emocionais primitivas, cujas tonalidades predispõem ao cuidado sensível do recém-nascido, porém, com o risco de desequilíbrio psíquico. Também é fato que certas qualidades da experiência materna são igualmente vividas na relação terapêutica, tais como a rotina confiável, a dedicação e a sensibilidade às necessidades do outro. Tal similitude nos leva a crer que o holding terapêutico protege a saúde mental da mãe, na mesma medida em que o holding materno facilita o caminho afetivo do bebê, configurando-se como recurso primordial na psicoterapia da maternidade.

\section{Considerações finais}

À guisa de conclusão deste trabalho, apresentamos algumas considerações inspiradas nos inúmeros casos que acompanhamos ao longo dos últimos dez anos.

Apesar do desamparo em que nasce, todo bebê é dotado de um potencial para o crescimento e busca mobilizar seu ambiente no sentido de ter suas necessidades atendidas. Os profissionais que se dispuserem a trabalhar com mães e bebês precisam ser cautelosos, dada a fácil identificação com a fragilidade do bebê e o esquecimento das necessidades da mãe. Tal situação pode impedir o estabelecimento de uma relação terapêutica confiável, uma vez que a mãe precisa que o terapeuta cuide dela, não de seu filho.

A mãe não é uma supermulher e, algumas vezes, apresenta-se tão fragilizada quanto seu bebê, necessitando cuidados especiais, como nos casos em que um colapso a ameace. Ela espera que o profissional a acolha e ajude na superação de dificuldades que surgiram em virtude das novas demandas da maternidade, não obtendo qualquer benefício do fato de ser julgada, desvalorizada ou submetida.

O terapeuta deve contar com as potencialidades criativas de cada mulher e fortalecê-las no sentido de encorajar a paciente a encontrar seu modo pessoal de ser mãe. Alinhados 
com a postura winnicottiana, também, não vemos sentido num trabalho pedagógico que priorize a técnica em detrimento de uma abordagem de acolhimento genuíno. Na presença de imaturidade emocional da mãe e/ou inadequação do apoio familiar e social, o atendimento psicológico mostra-se decisivo no estabelecimento do vínculo afetivo que garante o bem-estar da dupla mãe-bebê.

A experiência da maternidade conduz a fronteiras de nossa existência, em que sentimentos que imaginávamos enterrados e esquecidos parecem voltar à vida, enquanto outros são experimentados pela primeira vez. Em pontos de passagem como esse, a mãe pode ser alçada em direção a uma maior autonomia ou dominada por ansiedades ancestrais. É nessa fronteira que convidamos tanto o clínico como o pesquisador a trabalharem, aliando sensibilidade e rigor na compreensão e alívio do sofrimento humano. Nesse sentido, o atendimento psicológico vem figurar, para além de seu habitual enfoque terapêutico, como poderoso recurso psicoprofilático.

\section{Referências}

Aiello-Vaisberg, T. M. J., Silva, L. S., Granato, T. M. M., \& Felice, E. M. (2003). Tissant la grossesse point à point: Art-thérapie pour les femmes enceintes. Bulletin de Psychologie, 56, 807-809.

Aiello-Vaisberg, T. M. J., \& Granato, T. M. M. (2006). Ser e fazer na clínica winnicottiana da maternidade. Aparecida, SP: Ideias e Letras.

Bleger, J. (1967a). Estudio de la parte psicótica de la personalidad. In J. Bleger, Simbiosis y ambigüedad (pp. 82-162). Buenos Aires: Paidós.

Bleger, J. (1967b). Psicoanálisis del encuadre psicoanalítico. In J. Bleger, Simbiosis y ambigüedad (pp. 237-250). Buenos Aires: Paidós.

Couto, T. H. A. M., Tachibana, M., \& Aiello-Vaisberg, T. M. J. (2007). A mãe, o filho e a Síndrome de Down. Paideia (Ribeirão Preto), 17, 265-272.

Dolto, F. (1993). Cura psicanalítica com a ajuda da bonecaflor. In F. Dolto, No jogo do desejo (pp.133-189). Lisboa: Relógio D’Água. (Original publicado em 1949)

Ferenczi, S. (2002). Confusion of tongues between adults and the child. In S. Ferenczi, Final contributions to the problems and methods of psycho-analysis (pp. 156-167). London: Karnac. (Original publicado em 1933)

Granato, T. M. M. (2002). Tempo de gestar: Encontros terapêuticos à luz da preocupação materna primária. São Paulo: Landmark.

Granato, T. M. M. (2005). Ética materna. In T. M. J. AielloVaisberg \& F. F. Ambrosio (Orgs.), Cadernos ser e fazer: Reflexões éticas na clínica contemporânea (pp. 128-136). São Paulo: IPUSP.

Granato, T. M. M. (2007). Modelo de pesquisa em psicologia da saúde. In F. F. Bortoletti, A. F. Moron, J. Bortoletti Filho, M. U. Nakamura, R. M. Santana, \& R. Mattar (Orgs.), Psicologia na prática obstétrica: Abordagem interdisciplinar (pp. 141-150). São Paulo: Manole.
Granato, T. M. M., \& Aiello-Vaisberg, T. M. J. (2003a). Ser e fazer na maternidade contemporânea. Estudos de Psicologia (Campinas), 20(2), 71-76.

Granato, T. M. M., \& Aiello-Vaisberg, T. M. J. (2003b). Preocupação materna especial. Psicologia Clínica, 14(2), 87-92.

Granato, T. M. M., \& Aiello-Vaisberg, T. M. J. (2004). Tecendo a pesquisa clínica em narrativas psicanalíticas. Mudanças: Psicologia da Saúde, 12, 253-271.

Granato, T. M. M., \& Aiello-Vaisberg, T. M. J. (2005). Prímula e Narciso a caminho da preocupação materna primária. Mudanças: Psicologia da Saúde, 13, 364373.

Granato, T. M. M., \& Aiello-Vaisberg, T. M. J. (2008). I was looking for a different treatment. Psychoanalytic Review, 95, 655- 667.

Klein, M. (1985). Notas sobre alguns mecanismos esquizóides. In M. Klein, Inveja e Gratidão e outros trabalhos (pp. 17-43). Rio de Janeiro: Imago. (Original publicado em 1946)

Ogden, T. H. (2005). On holding and containing, being and dreaming. In T. H. Ogden, This art of psychoanalysis: Dreaming undreamt dreams and interrupted cries (pp. 93-108). London: Routledge.

Safra, G. (2004). A po-ética na clínica contemporânea. São Paulo: Ideias e Letras.

Searles, H. (1999a). The squizofrenic individual's experience of his world. In H. Searles, Contratransference and related subjects (pp. 5-27). Madison, WI: International Universities Press. (Original publicado em 1967)

Searles, H. (1999b). The function of the patient's realistic perceptions of the analyst in delusional transference. In $\mathrm{H}$. Searles, Contratransference and related subjects (pp. 196-227). Madison, WI: International Universities Press. (Original publicado em 1972)

Spurling, L. S. (2008). Is there still a place for the concept of therapeutic regression in psychoanalysis? The International Journal of Psychaonalysis, 89, 523-540.

Steiner, J. (1997a). Uma teoria dos refúgios psíquicos. In J. Steiner, Refúgios psíquicos (pp. 17-29). Rio de Janeiro: Imago. (Original publicado em 1993)

Steiner, J. (1997b). Problemas de técnica psicanalítica: Interpretações centradas no paciente e centradas no analista. In J. Steiner, Refúgios psíquicos (pp. 153-167). Rio de Janeiro: Imago. (Original publicado em 1993)

Van Gennep, A. (1984). The rites of passage. Chicago, IL: University of Chicago. (Original publicado em 1908)

Winnicott, D. W. (1971). Therapeutic consultations in child psychiatry. New York: Basic Books.

Winnicott, D. W. (1975a). Sonhar, fantasiar e viver. In D. W. Winnicott, O brincar e a realidade (pp. 45-58). Rio de Janeiro: Imago. (Original publicado em 1971)

Winnicott, D. W. (1975b). A criatividade e suas origens. In D. W. Winnicott, O brincar e a realidade (pp. 95-120). Rio de Janeiro: Imago. (Original publicado em 1971) 
Winnicott, D. W. (1988a). Preocupação materna primária. In D. W. Winnicott, Textos selecionados: Da pediatria à psicanálise (pp. 491-498). Rio de Janeiro: Francisco Alves. (Original publicado em 1956)

Winnicott, D. W. (1988b). Retraimento e regressão. In D. W. Winnicott, Textos selecionados: Da pediatria à psicanálise (pp. 427-435). Rio de Janeiro: Francisco Alves. (Original publicado em 1954)

Winnicott, D. W. (1988c). Aspectos clínicos e metapsicológicos da regressão dentro do setting psicanalítico (pp. 459-481). In D. W. Winnicott, Textos selecionados: Da pediatria à psicanálise. Rio de Janeiro: Francisco Alves. (Original publicado em 1954)

Winnicott, D. W. (1990a). Distorção do ego em termos de falso e verdadeiro self. In D. W. Winnicott, $O$ ambiente e os processos de maturação (pp. 128-139). Porto Alegre: Artes Médicas. (Original publicado em 1960)

Winnicott, D. W. (1990b). Teoria do relacionamento paternoinfantil. In D. W. Winnicott, $O$ ambiente e os processos de maturação (pp. 38-54). Porto Alegre: Artes Médicas. (Original publicado em 1960)

Winnicott, D. W. (1990c). A integração do ego no desenvolvimento da criança. In D. W. Winnicott, $O$ ambiente e os processos de maturação (pp. 55-61). Porto Alegre: Artes Médicas. (Original publicado em 1962)

Winnicott, D. W. (1994a). O medo do colapso. In C. Winnicott (Org.), Explorações psicanalíticas (pp.70-76). Porto Alegre: Artes Médicas. (Original publicado em 1963)

Winnicott, D. W. (1994b). Notas sobre o retraimento e regressão. In C. Winnicott (Org.), Explorações psicanalíticas (pp. 116-118). Porto Alegre: Artes Médicas. (Original publicado em 1965)

Winnicott, D. W. (1996). A mãe dedicada comum. In D. W. Winnicott, Os bebês e suas mães (pp. 1-11). São Paulo: Martins Fontes. (Original publicado em 1949)

Tania Mara Marques Granato é pós-doutoranda em Psicologia pelo Programa de Pós-graduação em Psicologia da Faculdade de Psicologia da Pontifícia Universidade Católica de Campinas, bolsista da FAPESP.

Tânia Maria José Aiello-Vaisberg é Professora Livre-Docente da Faculdade de Psicologia da Pontifícia Universidade Católica de Campinas, campus II. 